Stream: Inspiring Critical Thought

2017, Vol 9(1), pp. 36-42

(C) The Author(s), 2017

http://journals.sfu.ca/stream

\title{
Positioning Myself Between West and East
}

\author{
Xinnan Shi \\ School of Communication \\ Simon Fraser University
}

Why would communications scholars want to present their positionality to the public? This was the first question I asked myself when I came across the term "positionality". Throughout my studies, I have approached communication as social science, and I have thought about communications researchers as scientists. I certainly understand that the objects of research in social science are social phenomena such as social relations and institutions, and that these are difficult to explain with quantitative data most of the time. But for me, being a scientist means holding back personal emotions and being objective in the production of knowledge about society. I believe that even a single case study should offer explanations not just of its immediate context, but also of broader social problems or phenomena.

However, on learning more about positionality, I was reminded of Dr. Guobin Yang, a professor at the University of Pennsylvania. He gave a lecture at the Communication University of China in 2015 in which he reflected on his academic trajectory. It seems that research on the Cultural Revolution was part of his destiny. He did not realize the subtle influence of this historical event, which took place in his youth, until he went abroad to study. His prior knowledge of his home was challenged, and he became interested in what happened during that period in Chinese history.

Coming to study in Vancouver, a culturally diverse city, has similarly given me a rare opportunity to encounter not only Westerners, but also "Chinese" from multiple regions including Hong Kong and Taiwan. What I have learned and perceived before leaving Mainland China is being challenged each time I communicate with these people. The complicated political relationship between mainland China and Hong Kong not only exists at the government level but also influences people's everyday interactions. In fact, people label each other based on where they come from before getting to know one another.

These feelings and experiences are significantly amplified because I am positioned in a community that is substantially different from my home. This shock and challenge allows me to rethink my previous views about the return of Hong Kong to China as well as the lasting effects of a series of protests that have happened since 2014. This has made me wonder how common people like me think about the Umbrella Movement and present their views about it on the Internet. Like Yang, I feel that what I perceived before and what I am experiencing have shaped who I am today. These perceptions are also inextricably linked to my research. It is crucial for me to engage with and have an independent voice in the global discourse of Chinese issues, from a new perspective that I did not realize before. At the same time, it is important not to blindly cater to the Western democratic dis- 
course without taking Chinese local conditions into account.

For researchers, becoming conscious of their positionality does not mean that they will stop being impartial, or that they will express their opinions without substantiation. Rather, positionality allows researchers to examine and develop a clearer understanding of their own relationship to their studies, and to better inform their audience of the position in which they situate themselves. In this way, researchers can have an ongoing dialogue with their own research as well as with the audience of their work.

My research looks at the representation of political activities on the free online encyclopedia Wikipedia. I focus particularly on entries about the Umbrella Movement which was mobilized in Hong Kong in 2014 in response to changing governance arrangements between Hong Kong and China. I plan to use discourse analysis to study Wikipedia's coverage of the movement with the hope of demonstrating how power relations between editors shape the process of knowledge production.

In what follows, I reflect on my positionality in carrying out this work by answering three questions: What brought me to my topic? How will I conduct my research? And how is my research related to social justice? I conclude that positioning myself between the West and East and between the global and local allows me to reexamine my previous knowledge, and to incorporate these reflections into the formulation of my positionality. The real-life shock of communicating with other Chinese led me to realize that even on platforms such as Wikipedia, which is supposed to produce value-free knowledge, people are still not able to escape the giant and intangible shadow of the discursive hegemony of the West.

\section{What Brought Me to My Topic?}

In the book Observing the Observer: Understanding Ourselves in Field Research (Reinharz, 2011), the author argued that the researcher is not just objectively carrying out fieldwork, but should also be considered as an instrument that will significantly shape research processes and results. She provided a framework to assess the researcher's positionality which is divided into research selves, personal selves and situational selves. I use this framework to reflect on what drew me to my project and why I think it is important.

According to Reinharz, research selves are the selves concerned with doing the research (2011, p. 5). I find this part of myself is most related to my motivations for studying Wikipedia, especially the Talk Page where editors discuss how to structure and edit articles. I have a background in Communication and Education from the Communication University of China, so I came to Simon Fraser University with the intention of studying how media technologies impact education. The Internet is playing an increasingly important role in shaping the way people obtain knowledge. When people have questions these days, they go to Google and the first result to pop up is often a Wikipedia entry. This makes Wikipedia a primary point of access to knowledge, and a key technology shaping how education takes place.

In 2016, I had the opportunity to participate in the process of producing knowledge as an editor of a Wikipedia page. This experience caused me to start to paying attention to the Talk Page as a space where editors discuss their disagreements over a specific editing act, and attempt to reach 
consensus on what a page will say. I believe that this process-the process behind the public entry-reflects how people from different cultural and political backgrounds construct and are constructed by online knowledge. These are the conditions that led me to the research and I will carry through the study, as they will continue to shape my approach and questions.

Personal selves describe the researcher's personal life experiences, and how they carry them into a field of study. In other words, one's own prior life story serves as a precondition for the research, like a seed that has been planted in researcher's head a long time ago. It absorbs this researcher's everyday life, perceptions, ideas and opinions, etc. as the soil where it eventually grows into a knowledge product. Why did I choose this case study? It is through reflecting on myself and my personal experiences that I can offer an explanation as to why I decided to focus on the Wikipedia entries about the Umbrella Movement as a case study for my research.

Like Professor Guobin Yang and many other Chinese scholars and students, I found that studying abroad, especially in a western country, presents both challenges and opportunities. The most interesting thing I found after coming to Canada is not experiencing cultural shock brought by my interactions with foreign people, but getting to know how Chinese from different regions navigate social relations with each other in their everyday lives. Coming from mainland China, I experience embarrassment every time I communicate with "other" Chinese, especially with my Taiwanese landlady. I never discuss China-Taiwan relations with her and I doubt we ever will have this conversation. We both choose our words very deliberately to avoid unnecessary conflicts. For example, I always struggle when I need to use "China" or "mainland" to refer to my country. The former suggests that I assume Taiwan is not a part of China, while the latter implies the opposite. These everyday embarrassments create a dilemma between us and the same thing happens during my interactions with Hong Kong Chinese. Furthermore, I watched a documentary named Yellowing last year- a chance that allowed me to understand the Umbrella Movement from the point of view of the participants. It made me realize that Hong Kong's return to China in 1997, and subsequent changes in policy or governance, could not change local people's opinions and standpoints overnight.

These special experiences prompted me to wonder about how Chinese from different regions think about the Umbrella Movement. I also wondered how they might express their views about these events online in different contexts, and whether they might do so more openly if they were able to avoid the social pressures of daily life (such as my conversations with my Taiwanese landlady). Finally, I also wondered about how knowledge is shaped and presented through online negotiations, and what this means for how historical events are presented in online educational media. So, as you can see, these are more than just research questions; they are issues that preoccupied me as a person.

I am not able to fully reflect on my situational self yet because this is the self that is created through the process of conducting the research. However, I believe that researchers are constructed by discourse at the same time as their positionalities shape their study. This is a relationship of mutual influence and transformation between the researcher and what they are researching. Since doing research is an ongoing and a changing process, and since fieldwork takes a long time, one's positionality changes over the course of a research project. My view of the Umbrella Movement has already changed since I began the work of reviewing Wikipedia editors' conversations. Also, I am 
astonished to learn that how the story has been told quite differently on two pages. The editors of these pages hope to keep their own independence rather than to interact with and refer to each other, which shows the tension between English and local editors and the difficulty of local knowledge being presented on a global platform. I did not expect this before beginning the research. Researchers need to learn how to make sense of their ever-changing experiences during the research process, and how to incorporate transformations of the situational self into their studies.

\section{How Am I Going to Do My Research?}

In addition to life experiences, research methods are another set of glasses through which we can see our research topic. Choosing a specific method over others can signal the role a scholar wants to play, and the position s/he wants to occupy in the process of conducting research. Methods also partially determine what the research objects are to me and who I am to them.

In my study, I am going to conduct a critical discourse analysis of conversations on Wikipedia Talk Pages that are related to the Umbrella Movement. Discourse analysis is conducted under the presupposition that reality is socially-constructed and that there is no absolute truth out there, waiting to be perceived by objective observers. We are all suspended in a multitude of discourses that overlap with each other, and we make sense of our experiences through these discourses. As Phillips and Hardy (2002) said in their book, "without discourse, there is no social reality, and without understanding discourse, we cannot understand our reality, our experiences, or ourselves" (p.2).

As an outside observer, who is neither a participant in the Umbrella Movement nor an editor of the Wikipedia entry, I am still being socially constructed, and this makes my view of the movement, and of texts that circulate about it on Wikipedia, different from anyone else in the world. Even though I have knowledge of how to conduct a structured, qualitative investigation, my three selves are embedded in every step of the research process, from data collection to analysis and theorization. I hope to show how knowledge of the Umbrella Movement came into being and how it was shaped by people from culturally diverse backgrounds. Some might expect this to be objective work that has nothing to do with my viewpoint of the movement itself. However, my own standpoint will inevitably shape certain preliminary assumptions, as well as the results that are built upon them, which means that my work will not be impartial, nor should that be expected. For example, as I conduct a discourse analysis, I may value some texts over others and this might exert an impact on my study. I am not saying that I am necessarily partial to texts that I identify with, but I need to admit that researchers have blind spots, and their works reflect what they believe to be important.

Discourse analysis is an interpretative and reflective process. It is different from journalism, which aims to provide the full story with opinions from multiple parties concerned. Researchers contribute to producing knowledge by representing those who they think should be listened to, and sharing their original, considered interpretation. Clarifying one's positionality should not be viewed as opening researchers up to criticism or exposing a researcher's vulnerabilities, but rather, it should be seen as a way to help us avoid falling into the trap of unreflective positivism or obsessive navel-gazing.

At first, I planned to do a simple discourse analysis, just focusing on how editors create consen- 
sus in the process of knowledge production, not involving issues of social relations and power. But with further contemplation, I realized that tensions between the two sides of the political power dynamic lurk behind every single sentence. The geopolitical relationship between Mainland China and Hong Kong and the discursive impact of the West cannot be overlooked if I intend to get a full picture of the knowledge production process. Therefore, I have decided that critical discourse analysis is a better fit with my project.

Critical discourse analysis presumes that there are unequal power relations at work in the social world, and emphasizes how the dominant group legitimates and maintains this relationship by controlling texts (van Dijk,1993). It is interesting to note that Hong Kong community presents itself differently in the English and Chinese contexts. Compared to the English version, the discourse on the Chinese page is overwhelmingly dominated by a group of pro-democracy activist editors. Not only do they highlight violent conflict between protesters and the police, and cite sources from liberal media to back up their edits, but some of them even indiscriminately attacked editors who disagree with their arrangements of the content, accusing them of being propagandizing for People's Republic of China. This process is what gave rise to the dominant version of the story of the Umbrella Movement which is what we see in the Wikipedia page on the topic. It is a process that silenced many voices. Instead of considering a bottom-up framework, I take the position of those unspoken and unheard voices, thereby criticizing how the dominant voices produce and reproduce their discourse. Discourse analysis cannot be neutral and it does not even aim to be objective. It is not simply a technique. Rather it is a methodology that provides us with a way to observe and explain social reality.

\section{How Does My Project Relate to Social Justice?}

While the concept of social justice may seem abstract for some people, it is embedded in the experience of everyday life. It cannot only be achieved by laws, regulations and policies at a macro level, but must also be shaped by ordinary people's perceptions, opinions and actions. We either legitimate the existing state of social justice or challenge it. Being a knowledge producer who is studying knowledge production, I am aware of the injustice embedded within our epistemic world. With the experience of studying abroad, I am even more sensitive to it.

There is a huge gap between Wikipedia in Chinese and English, in terms of the number of articles and the degree of engagement. Although some Wikipedia entries are banned in Mainland China and this may have an influence on the Chinese community, we cannot deny that the English version is in a dominant position compared to any other languages. And some Chinese editors would rather participate in the English than the Chinese community. This reflects unequal knowledge production and dissemination between the West and East.

The reason I decided to focus on articles on Umbrella Movement is that I wanted to contribute, even if only a little bit, to bridging the gap between the West and East - the dominant and dominated in global knowledge discourse as a knowledge producer and a communicator. Some Chinese scholars argue that some interpretations of Chinese issues given by western scholars are not "objective" or "fair" because they are produced and reproduced within an unjust epistemological frame- 
work. By analyzing two different processes of storytelling of the movement, I expect to provide an example of how local communities manage their epistemological dilemmas. These communities struggle over the documentation of history, and they do so without being able to escape the hegemonic discursive impact of the West at a global level.

When I reflect on my methodology, I find that it also relates to social justice. By applying critical discourse analysis to my study, I am able to see how a text reflects and constructs social reality and how power relations play ideological and cognitive roles in this process. To put it in another way, I can better see how people understand social justice and how they incorporate texts and actions into discourse so as to maintain or resist existing power structures (Phillips, Lawrence, \& Hardy, 2004). In the two different versions of the Umbrella Movement Wikipedia article, the "truth" of the event is demonstrated in different ways by editors making specific editorial choices and emphasizing different topics. Facing a global or local audience, social justice is constructed variously in response to different power structures and dynamics.

Having said this, doing an interpretative and reflective work means that I can never really ascertain that I truly represent those unheard voices. The discourse constructed within Wikipedia texts will be known to the public through my work. But I can never be entirely sure if my interpretation is what the authors intended. I consider this to be an imbalance of power relations between the researcher and researched, even though there is nothing I can do to change it. In this relationship, I am the researcher with initiative and agenda, but they are the researched, and are rendered passive.

I can take some comfort in an argument offered by Etherington (2004), who says that "by using reflectivity in research we close the illusory gap between researcher and researched and between the knower and what is known" (p.32). Researchers cannot realize that they are taking a "reality", which can be biased or unjust, for granted unless they keep themselves "open" to the audience and make clear how their three selves infiltrate into research processes. This introspection is not a supplement to our study, but rather is itself crucial to the research process.

What we can conclude from this is that knowledge production is an articulation of power structures. Even though people consider Wikipedia to be a reliable source of knowledge, questions remain: which version of reality is legitimated and in the service of whom. Positioning myself at the crossroads of West and East, local and global, I have a chance to rethink my prior knowledge. I can examine the disjuncture between knowledge that comes from being a member of dominant Chinese versus the knowledge that comes from the perspective of the marginalized peoples within Western society. The clash of these two perspectives enables me to truly realize the significance of a researcher's positionality. This realization has reshaped my three selves- my research self, personal self and situational self-and have caused me to pursue an examination of the behind-the-scenes power dynamics that shape online knowledge production. Being reflective of how I position myself in relation to my study constantly reminds me of my responsibility to those unheard voices, and makes me want to ensure that I represent them justly. Like anyone in the world who is unable to get rid of the subliminal influence of global epistemological hegemony, this process of finding answers is a constant introspection in my life. 


\section{References}

Etherington, K. (2004). Becoming a reflexive researcher: Using ourselves in research. Philadelphia, PA: Jessica Kingsley Publishers.

Phillips, N. \& Hardy, C. (2002). Discourse analysis: Investigating processes of social construction. London, UK: Sage Publications.

Phillips, N., Lawrence, T. B., \& Hardy, C. (2004). Discourse and institutions. Academy of Management Review, 29(4), 635-652.

Reinharz, S. (2011). Observing the observer: Understanding ourselves in field research. New York, NY: Oxford University Press.

van Dijk, T.A. (1993). Principles of critical discourse analysis. Discourse \& Society. 4(2), 249-283. 